


\title{
Sætningskompleksitet i dansk
}

\author{
Af Mads Christiansen
}

This article gives an introduction to linguistic complexity and investigates the complexity of sentences in Danish from a diachronic perspective. By taking a recursion-based approach to the phenomenon, it can be shown that in the old part of the corpus (eighteenth/ nineteenth century) sentences are more complex than in the new part (twentieth/twentyfirst century). For instance, the older texts are found to contain more clauses per sentence, more clause complexes and more subordinate clauses of a higher degree of dependency than the contemporary texts. The observation that a similar development occurs in Swedish and German should be considered when trying to explain the process of complexity reduction.

\section{Indledning}

I løbet af de seneste godt og vel 15 år har kompleksitetsforskningen etableret sig som en fast bestanddel af den i forvejen vidtforgrenede sprogvidenskabelige teoridannelse. Derom vidner en efterhånden lang række publikationer, som undersøger konceptet fra forskellige perspektiver i et bredt udvalg af sprog. ${ }^{1}$ Intuitivt har mange reflekterede sprogbrugere sikkert en idé om, hvad begrebet dækker over, og de fleste vil formentlig tilslutte sig det synspunkt, at juridisk sprog generelt er af en mere kompleks beskaffenhed end sproget i dagspressen. Men hvad forstås egentlig ved kompleksitet som lingvistisk fagterm? Hidtil er det ikke lykkedes forskningen at opstille en konsensusbåret definition endsige klarlægge, hvordan konceptet bedst kan operationaliseres. Det skyldes ikke mindst, at kompleksitet - i modsætning til fx ord og sætning - ikke betegner en bare nogenlunde entydig objektsproglig størrelse, men er af mere abstrakt karakter (Hennig 2017b: 8). Til trods for disse terminologiske vanskeligheder er målet med denne artikel at vise, at begrebet har sin berettigelse, også i beskrivelsen af dansk. ${ }^{2}$ Artiklen består af følgende dele: Efter en introduktion til den lingvistiske kompleksitetsforskning demonstreres det, hvordan konceptet kan operationaliseres på periodeniveau. Ved en periode forstås en syntaktisk enhed bestående af den eller de hoved-/ledsætninger, som optræder imellem to punktummer eller tilsvarende inter-

1 Til illustration kan nævnes artiklerne i Hennig (2017a), Kortmann/Szmrecsanyi (2012a) og Miestamo/Sinnemäki/Karlsson (2008).

2 Det mig bekendt eneste bidrag, som beskæftiger sig med (syntaktisk) kompleksitet i dansk, er Blom (2011), der analyserer et korpus bestående af manuskriptbaserede radionyheder. 
punktionstegn, dvs. semikolon, spørgsmåls- og udråbstegn. Dernæst præsenteres et til formålet sammensat korpus efterfulgt af en diakront anlagt kompleksitetsanalyse af periodestrukturer i dansk. Endelig sammenfattes de væsentlige resultater.

\section{Den lingvistiske kompleksitetsforskning}

\subsection{Forskningshistorisk overblik}

Historisk betragtet falder kompleksitetsforskningen i tre faser. At den metodisk-teoretisk funderede tilgang til emnet er af yngre dato, betyder ikke, at fænomenet har været upåagtet af tidligere tiders sprogvidenskab. Omdrejningspunktet har historisk set været spørgsmålet, om alle sprog kan siges at være lige komplekse. Disse overvejelser kan spores tilbage til den sammenlignende sprogvidenskab i det 19. århundrede. I romantikkens ånd antog man en nær sammenhæng mellem sprog og kultur, således at kulturområder, der tillagdes en særlig status, rådede over udpræget komplekse sprog. Paradeeksemplerne var græsk, latin og sanskrit - alle grundlæggende for europæisk civilisation (Fischer 2017: 27-30). Titlen på Wilhelm von Humboldts Über die Verschiedenheit des menschlichen Sprachbaues und ihren Einfluss auf die geistige Entwickelung des Menschengeschlechts (1836) illustrerer essensen i dette tankesæt: Sprog og kultur betragtedes som to sider af samme sag, og komplekse tanker lod sig bedst udtrykke i komplekse sprog (Baechler 2017: 5).

Det 20. århundredes kompleksitetsforskning, som særligt var udbredt i strukturalistiske kredse, markerede et brud med denne symbiotiske opfattelse. Retningsgivende blev nu det synspunkt, som Hockett (1958) anlagde i nedenstående passage fra en lingvistisk lærebog:

Impressionistically it would seem that the total grammatical complexity of any language, counting both morphology and syntax, is about the same as that of any other. This is not surprising, since all languages have about equally complex jobs to do, and what is not done morphologically has to be done syntactically (Hockett 1958: 180f). ${ }^{3}$

3 Det er værd at bemærke, at Hockett (1958) ikke var ude i et kompleksitetsteoretisk ærinde, men blot nævnte emnet en passant (Hennig 2015: 164). Det kan derfor undre, at dette udsagn er blevet tillagt så stor betydning af den senere forskning. 
Det nye var, at Hockett (1958) antog, at der fandtes en form for udligningsmekanisme, som bevirkede, at høj kompleksitet på ét sprogligt niveau modsvaredes af lav kompleksitet på et andet. Ultimativt implicerede det, at alle sprog var omtrent lige komplekse - et synspunkt, der kan ses som et ideologisk opgør med det 19. århundredes sammenkobling af sprog og kultur (Sampson 2009: 4). Imidlertid er validiteten af denne antagelse, som ofte benævnes ALEC (»all languages are equally complex«) eller ækvikompleksitetshypotesen, i de senere år blevet draget i tvivl fra forskellig side. Ifølge Deutscher (2009) er der tale om et aksiom. Empiriske belæg savnes.

I det 21. århundrede har sproglig kompleksitet oplevet en stigende faglingvistisk interesse. Fænomenet betragtes i dag atter som en variabel størrelse - dog uden at dette har implikationer for, hvilken status de respektive kulturer tilskrives (Baechler 2017: 6). Der hersker desuden bred enighed om, at kompleksitet er målbar inden for afgrænsede sproglige områder som fx syntaks, morfologi og fonologi. Generelt opereres der altså ikke med en global, men lokal forståelse af konceptet. Som Miestamo (2008: 30) påpeger, er dette metodisk fordelagtigt. I modsætning til den globale tilgang udmærker den lokale sig nemlig ved hverken at opvise et repræsentativitets- eller sammenligningsproblem. Dels synes det ikke praktisk muligt at beskrive et sprogs kompleksitet på alle lingvistiske niveauer, dels ikke metodisk forsvarligt at sammenligne kompleksitet på tværs af sproglige niveauer - to antagelser, der er centrale i det globale perspektiv. Som talrige artikler har demonstreret, udgør en lokalt forankret begrebsforståelse derimod en frugtbar tilgang til kompleksitetsfænomener. $^{4}$

\subsection{Relativ vs. absolut kompleksitet}

Grundlæggende skelnes mellem relativ og absolut kompleksitet. Den relative tilgang hviler på den antagelse, at sproglige strukturers kompleksitet står i nær sammenhæng med, hvor vanskelige de er at processere/tillære. Afgørende er naturligvis, hvem der processerer/tillærer. Kusters (2008) opererer i den henseende med en såkaldt 'generalized outsider':

4 Der henvises i den forbindelse til oversigten hos Kortmann/Szmrecsanyi (2012b: 9), som oplister udvalgte publikationer på baggrund af, hvilket sprogligt niveau de opererer på. 
This person speaks a first language, and is not familiar with the second language in question, nor with the customs and background knowledge of the speech community. He or she is primarily interested in using language for communicative purposes in the restricted sence of the word, and not in all kinds of verbal play, ritual exchanges, and poetic uses (Kusters 2008: 9).

Kusters (2008) er med rette blevet kritiseret for at fokusere på en eksklusiv gruppe af sprogbrugere, hvilket gør det vanskeligt at drage generelle slutninger på grundlag af hans 'generalized outsider'-koncept (Miestamo 2008: 25f.). I størstedelen af fremmedsprogsundervisningen, som den praktiseres i en nutidig dansk kontekst, er det eksempelvis usandsynligt, at lørneren ikke råder over et forudgående kulturkendskab som følge af geografisk nærhed, mediepåvirkning m.v. Genetisk sprogslægtskab og sprogkontakt mellem dansk og centrale fremmedsprog som engelsk og tysk bidrager endvidere til, at lørneren indirekte besidder et vist forhåndskendskab til disse sprog. Samlet set fremstår relativ kompleksitet - i hvert fald i den version, som Kusters (2008) advokerer for - som et koncept, der er vanskeligt at operationalisere. ${ }^{5}$

Den absolutte tilgang tager sit udgangspunkt i sprogsystemet, ikke i bestemte individers omgang med sproget. Grundtanken er, at kompleksitet kan forstås som antallet af nærmere definerede elementer på et bestemt sprogligt niveau. De to mest udbredte kompleksitetsmål er kendt som hhv. 'Kolmogorov-kompleksitet' og 'Gell-Mann-kompleksitet'. I det første tilfælde siges $\mathrm{x}$ at være mere kompleks end $\mathrm{y}$, hvis den korteste beskrivelse af $\mathrm{x}$ er længere end den korteste beskrivelse af $\mathrm{y}$. I det andet tilfælde betragtes x som mere kompleks end $y$, hvis den korteste beskrivelse af de regulariteter eller strukturmønstre, som kendetegner $\mathrm{x}$, er længere end den korteste beskrivelse af de regulariteter eller strukturmønstre, som kendetegner y. ${ }^{6}$ Som det fremgår, baserer begge definitioner sig på en beskrivelse af bestemte forhold. Denne middelbare tilgang skal ses i lyset af, at kompleksitet som nævnt er en abstrakt størrelse, der kun kan indkredses rent deskriptivt på grundlag af en lokal operationalisering.

5 Den relative tilgang kan dog i visse sammenhænge have sin berettigelse, hvilket Kusters (2008) demonstrerer i en fleksionsmorfologisk kompleksitetsanalyse af forskellige varieteter af det sydamerikanske sprog quechua.

6 Der er tale om min gengivelse af de tysksprogede definitioner hos Fischer (2017: 21f.). I begge tilfælde dækker x og y over et lokalt forankret kompleksitetsfænomen. 
Det, som adskiller de to definitioner, er spørgsmålet om, hvad der skal beskrives. Kolmogorov-kompleksitet måler et objektsprogligt inventar. Eksempelvis råder dansk som bekendt over relativt mange vokallyde og kan følgelig siges at opvise en mere kompleks vokalisme end fx tysk. Gell-Mann-kompleksitet måler ikke et objektsprogligt inventar, men derimod de principper, som regulerer et bestemt fænomen. Ud fra denne logik er klusilerne i dansk mindre komplekse end i tysk, da kun tysk opviser regler for udlydshærdning (jf. Fischer 2017: 23). ${ }^{7}$ Det er værd at betone, at der bag de to tilgange ikke ligger radikalt divergerende forståelser af, hvad kompleksitet er, men at forskellen mestendels består i målemetoden. I praksis vil det ofte være formålstjenligt at kombinere de to koncepter.

\subsection{Operationalisering på periodeniveau}

I forlængelse af disse generelle betragtninger skal det drøftes, hvordan kompleksitetsbegrebet kan operationaliseres på periodeniveau. ${ }^{8}$ Det forudsætter, at det specificeres, hvad der forstås ved syntaktisk kompleksitet. Culicover (2013) opererer med følgende definition:

The term 'syntactic complexity' is often used to refer to the hierarchical structure of sentences. Other things being equal, it is assumed that flatter structure is less complex, while greater embedding constitutes greater syntactic complexity. Thus, on this view coordination is less complex than subordination, and nominal expressions are less complex than clausal ones (Culicover 2013: 19).

Denne forståelse af syntaktisk kompleksitet som subordination på sætningsniveau (rekursion) giver anledning til at diskutere to forhold. For det første er det ikke fuldstændig afklaret, om også koordinerede strukturer i visse tilfælde kan betragtes som komplekse. Det springende punkt er her, om kompleksitetsbegrebet dependensgrammatisk set bør reserveres til eksempler, hvor eksisterende strukturer udbygges, eller tillige bør omfatte tilfælde, hvor nye strukturer etableres (Hennig/Emmrich/Lotzow 2017: 176). I betragtning af, at der på nuværende tidspunkt synes at her-

7 Udlydshærdning betegner det forhold, at de tyske leniskonsonanter $b d g$ i ord- og stavelsesudlyd erstattes af fortiskonsonanterne $p t k$.

8 Periodebegrebet bestemmes i kapitel 1. Se også Christiansen (i trykken) for lignende overvejelser. 
ske konsensus om, at subordination udgør en hensigtsmæssig syntaktisk operationalisering, videreføres dette synspunkt i det følgende.

For det andet bemærkes, at Culicover (2013: 19) anfører, at kompleksitet på nominalfraseniveau er mindre udpræget end på sætningsniveau. Umiddelbart synes dette plausibelt for sprog som dansk og engelsk. Men retter man blikket mod tysk, er forholdene mindre entydige. Her realiserer participialattributter ofte deres verbale valensegenskaber i prænominal position, hvilket medfører en højere grad af subordination og dermed kompleksitet på nominalfraseniveau (Christiansen 2018). Et eksempel ${ }^{9}$ kunne være »dieser kostenlose, tief im Menschen ruhende und häufig unerschlossene Rohstoff«. På dansk kan det gengives med »dette gratis og hyppigt uudnyttede råstof, som hviler dybt i mennesket«, der som følge af relativsætningen opviser større kompleksitet på sætningsniveau.

Endelig skal det nævnes, at Blom (2011) også baserer sin undersøgelse på andre operationaliseringsprincipper end subordination, bl.a. den såkaldte 'Dependency Locality Theory', hvilket skal ses i lyset af, at han til dels abonnerer på en relativ begrebsforståelse - uden dog at eksplicitere dette. Som det fremgår af Karlsson (2009), er det også muligt at inddrage topologiske forhold i beskrivelsen af sætningskompleksitet. Da det er vanskeligt at sammenligne kompleksitet som et topologisk og hierarkisk fænomen, ses i det følgende bort fra topologien. ${ }^{10}$

\subsection{Korpus}

Undersøgelsen bygger på uddrag af fire historievidenskabelige værker fra det 18. til det 21. århundrede. Det drejer sig om Dannemarks Riges Historie af Ludvig Holberg, Haandbog i Foedrelandets Historie af Carl Ferdinand Allen, Danmarks Historie af Erik Arup og Danmarks historie - $i$ grundtrcek i form af et uddrag forfattet af Erik Ulsig. ${ }^{11}$ Fra hvert værk analyseres manuelt et uddrag på ca. 5000 ord af tematisk beslægtede kapitler

9 Eksemplet stammer fra Christiansen (2018: 334).

10 En fagfællebedømmer foreslår at betegne det undersøgte fænomen som stilistisk (og altså ikke lingvistisk) kompleksitet. Argumentet lyder, at det ikke er de mulige lingvistiske strukturer, som behandles, men udnyttelsesgraden af bestemte strukturer. I dette bidrag fastholdes den gængse terminologi, men det medgives, at synspunktet er interessant og fortjener en systematisk behandling $i$ anden sammenhæng.

11 En oversigt over det empiriske materiale i de anvendte udgaver findes i afsnit 5.1. Hvad angår de respektive teksters affattelsestidspunkt, er Holberg fra 1732-35 (trebindsværk), Allen fra 1840, Arup fra 1925-55 (trebindsværk) og Ulsig fra 2000. 
(omhandlende dansk senmiddelalder og særligt Christian II). Det er evident, at omfanget af dette korpus betyder, at undersøgelsen skal betegnes som et pilotstudie. Fremtidig forskning må efterprøve resultaterne ved hjælp af større korpora og i den forbindelse inddrage forskellige genrer. Dette forhold til trods burde det på grundlag af det opstillede korpus være muligt at udlede hovedtræk i udviklingen af dansk sætningskompleksitet.

Forud for den diakrone undersøgelse skal visse termini forklares. Det anvendte sætningsbegreb begrænser sig ikke til kombinationen af verballed og subjekt (neksus), men bygger alene på tilstedeværelsen af et finit verbum. En selvstændig sætning betegner en periode bestånde af kun én sætning. I modsætning hertil dækker begrebet storsætning over perioder indeholdende mindst to sætninger. Der skelnes mellem parataktiske og hypotaktiske storsætninger. Hvor førstnævnte udelukkende omfatter hovedsætninger, indgår der i sidstnævnte mindst én ledsætning. ${ }^{12}$

\section{Sætningskompleksitet før og nu}

Den følgende tabel giver et overblik over antallet af ord samt det gennemsnitlige antal ord og delsætninger pr. periode i det undersøgte korpus:

$\begin{array}{llll} & \text { Ordantal } & \text { Ord pr. periode } & \begin{array}{l}\text { Delsætninger pr. } \\ \text { periode }\end{array} \\ \text { Holberg } & 5034 & 33,3 & 3,7 \\ \text { Allen } & 5019 & 27,6 & 2,8 \\ \text { Arup } & 5020 & 21,3 & 2,0 \\ \text { Ulsig } & 5002 & 20,3 & 2,0\end{array}$

Tabel 1: Overblik over det empiriske materiale

Som det fremgår, reduceres den gennemsnitlige periodelængde markant fra Holberg (33,3 ord pr. periode) til Ulsig (20,3 ord pr. periode). ${ }^{13}$ Ikke

12 Storsætningsbegrebet er overtaget fra Hansen (1967: 69f.), der dog synes at reservere det til sådanne tilfælde, som i det foreliggende bidrag betegnes hypotaktiske storsætninger.

13 Det bemærkes, at den gennemsnitlige periodelængde hos Ulsig ( 20,3 ord pr. periode) ikke ligger langt fra den gennemsnitlige periodelængde i moderne dansk pressesprog $(20,5$ ord pr. periode) (Christiansen i trykken). 
overraskende gør det samme sig gældende for det gennemsnitlige antal delsætninger pr. periode. Mens der kan konstateres relativt store forskelle de tre første tekster imellem (perioderne er mere omfangsrige hos Holberg end hos Allen, som igen opviser længere perioder end Arup), er der ingen nævneværdige forskydninger mellem Arup og Ulsig. Om dette kan ses som et udtryk for, at periode- og delsætningslængden generelt betragtet forholder sig stabil i det 20. århundrede, må fremtidig forskning undersøge. Under alle omstændigheder kan man på ovenstående grundlag - hvor interessante de dokumenterede udviklingslinjer end måtte være - kun i begrænset omfang drage konklusioner om sætningskompleksitet, der som nævnt afhænger af rekursion.

Nedenstående oversigt viser det relative antal selvstændige sætninger, parataktiske og hypotaktiske storsætninger:

$\begin{array}{llll} & \begin{array}{l}\text { Selvstændige } \\ \text { sætninger }\end{array} & \begin{array}{l}\text { Parataktiske } \\ \text { storsætninger }\end{array} & \begin{array}{l}\text { Hypotaktiske } \\ \text { storsætninger }\end{array} \\ \text { Holberg } & 13,9 \% & 5,3 \% & 80,8 \% \\ \text { Allen } & 18,7 \% & 6,0 \% & 75,3 \% \\ \text { Arup } & 39,7 \% & 10,9 \% & 49,4 \% \\ \text { Ulsig } & 38,2 \% & 16,5 \% & 45,4 \%\end{array}$

Tabel 2: Diverse scetningsstrukturer

De væsentlige forskydninger, som fremgår af oversigten, kan alle betragtes som tegn på, at sætningskompleksiteten på periodeniveau aftager $\mathrm{i}$ løbet af det undersøgte tidsrum. De selvstændige sætninger, der alt andet lige er hovedsætninger, altså pr. definition ikke komplekse, optræder ganske vist hos både Holberg (1) og Allen (2), men i mindre omfang end hos Arup (3) og Ulsig (4):

(1) Hans Død foraarsagede stoor U-eenighed i Riget. (Holberg: 9)

(2) Christiern den Anden var den undertrykte Bondestands Ven og Beskytter. (Allen: 274)

(3) En herredag blev indkaldt til København til 24. juni. (Arup: 324)

(4) Også i Norge var der bondeuro. (Ulsig: 85) 
Antallet af parataktiske storsætninger, der i lighed med de selvstændige sætninger bør betragtes som et udtryk for lav periodekompleksitet, er også støt stigende. Hos Holberg (5) og Allen (6) er de altså ikke så hyppigt belagt som hos Arup (7) og Ulsig (8):

(5) Den samme var kun fattig og af ringe Extraction, thi hendes Moder Sibrit havde fordum været Høkerske udi Amsterdam, og der saalt Æbler og Nødder, men nærede sig da med at holde Vertshuus i Bergen. (Holberg: 5f.)

(6) Efter Overgivelsen af Stæke blev Gustav Trolle ikke blot afsat fra sin Værdighed som Ærkebisp, men endog indespærret i et Kloster, og hans befæstede Borg jævnedes med Jorden. (Allen: 265)

(7) Mogens Gøye blev tyve aar gammel hofsinde, kammerjunker, 1492, ti aar efter fik han sin første forlening, Torup, nu Frisenvold, med Gislev-, Galten- og Hovlbjerg h., 1503 blev han rigsraad, 1505 fik han Aalborghus i len med otte herreder. (Arup: 332)

(8) Ligesom i Danmark voksede godsejernes rettigheder i det østelbiske Europa i hidtil uset omfang i middelalderens slutning, og der foregik en uddelegering af centralmagtens beføjelser. (Ulsig: 100)

Udviklingen af de hypotaktiske storsætninger understøtter det indtryk, at sætningskompleksiteten gradvis aftager. Hos Holberg (9) og Allen (10) er denne rekursive strukturtype klart dominerende, mens den hos Arup (11) og Ulsig (12) kun udgør omkring halvdelen af de undersøgte sætningsstrukturer:

(9) Efter at Dansen var til Ende, og det var bleven silde paa Aftenen, gik den eene bort efter den anden, og Dyveke tillige med hendes Moder Sibrit blev til sidst. (Holberg: 6)

(10) Borger- og Bondestanden, hvis Kræfter vare udtømte i Striden, maatte derefter i lang Tid taalmodigen bære Aaget. (Allen: 262)

(11) Derfor opsatte rigsraadet en fortegnelse over alle de mange punkter, hvori kong Hans havde brudt sin beseglede haandfæstning, rigets forfatning. (Arup: 325) 
(12) Det danske rigsråd henvendte sig til grev Adolf af Holsten, der siden 1440 også var retmæssig hertug af Slesvig. (Ulsig: 85)

På denne baggrund overrasker det ikke, at distributionen af hoved- og ledsætninger udvikler sig på følgende vis:

$\begin{array}{lll} & \text { Hovedsætninger } & \text { Ledsætninger } \\ \text { Holberg } & 41,6 \% & 58,4 \% \\ \text { Allen } & 50,7 \% & 49,3 \% \\ \text { Arup } & 61,7 \% & 38,3 \% \\ \text { Ulsig } & 67,8 \% & 32,2 \%\end{array}$

Tabel 3: Fordeling af hoved- og ledscetninger

Mens det relative antal hovedsætninger stiger, forholder det sig omvendt for ledsætningernes vedkommende. Hvad angår ledsætningernes grad, tegner sig følgende billede:

\begin{tabular}{lllll}
\multicolumn{5}{c}{ Ledsætninger } \\
1. grad & 2. grad & 3. grad & $>3$. grad \\
Holberg & $59,1 \%$ & $23,2 \%$ & $9,9 \%$ & $7,7 \%$ \\
Allen & $74,1 \%$ & $19,4 \%$ & $4,9 \%$ & $1,6 \%$ \\
Arup & $77,7 \%$ & $19,6 \%$ & $2,2 \%$ & $0,5 \%$ \\
Ulsig & $79,7 \%$ & $19,0 \%$ & $1,3 \%$ & $0,0 \%$
\end{tabular}

Tabel 4: Ledscetningernes grad

Hvor ca. to femtedele af ledsætningerne hos Holberg er af mere end 1. grad, er ca. tre fjerdedele af ledsætningerne hos Allen, Arup og Ulsig af 1. grad. Kun hos Holberg optræder ledsætninger af mere end 3. grad med en vis hyppighed; i tekstuddraget af Ulsig er de slet ikke belagt. Dette billede understøttes af følgende oversigt, som illustrerer antallet af delsætninger pr. hypotaktisk storsætning: 


\begin{tabular}{|c|c|c|c|c|c|}
\hline \multicolumn{6}{|c|}{ Delsætninger } \\
\hline & $\begin{array}{l}2 \\
\text { delsætninger }\end{array}$ & $\begin{array}{l}3 \\
\text { delsætninger }\end{array}$ & $\begin{array}{l}4 \\
\text { delsætninger }\end{array}$ & $\begin{array}{l}5 \\
\text { delsætninger }\end{array}$ & $\begin{array}{l}>5 \\
\text { delsætninger }\end{array}$ \\
\hline Holberg & $23,0 \%$ & $21,3 \%$ & $20,5 \%$ & $11,5 \%$ & $23,8 \%$ \\
\hline Allen & $34,3 \%$ & $33,6 \%$ & $13,9 \%$ & $10,9 \%$ & $7,3 \%$ \\
\hline Arup & $48,3 \%$ & $28,8 \%$ & $18,6 \%$ & $2,5 \%$ & $1,7 \%$ \\
\hline Ulsig & $54,0 \%$ & $27,4 \%$ & $14,2 \%$ & $1,8 \%$ & $2,7 \%$ \\
\hline
\end{tabular}

Tabel 5: Delscetninger pr. hypotaktisk storsatning

Hypotaktiske storsætninger indeholdende fem eller flere delsætninger virker ud fra en nutidig betragtning påfaldende, mens de ikke er sjældne hos hverken Holberg (13) eller Allen (14). Hos Arup (15) og Ulsig (16) består den prototypiske hypotaktiske storsætning derimod af to delsætninger:

(13) Dog kunde man mærke, at de ingen Lyst havde til Foreeningen, endeel, efterdi de havde efter Svante Stures Død [...] udvaldt hans Søn Steen Sture til Rigets Forstandere, endeel ogsaa, efterdi de foregave, at den Hylding, de havde gjort Hertug Christian 1499 var ikke lovlig, efterdi den var skeed af Raadet alleene uden Borgernes og Bøndernes Samtykke. (Holberg: 9)

(14) Christiern den Andens Regjering har faaet en særegen Betydning i Danmarks Historie derved, at den blev Anledning til en Kamp mellem de høiere og lavere Stænder, hvori disse, som længe taalmodigen havde baaret Adelens og Geistlighedens Aag, gjorde et kraftigt Forsøg på at afryste dette. (Allen: 261)

(15) Efterat den nye rigsinstitution, stændermødet, var kommet op, blev herredag betegnelsen for et rigsmøde alene af rigets adelige herremænd. (Arup: 324)

(16) De to konger kom med det samme i strid om Gotland, hvor Erik af Pommern fortsat herskede. (Ulsig: 85)

Samlet set kan der konstateres en reduktion i sætningskompleksitet fra Holberg over Allen og Arup til Ulsig. Det rejser to centrale spørgsmål: 
A) Er der tale om en særlig dansk udvikling?

B) Hvordan kan den beskrevne kompleksitetsreduktion forklares?

Ad A) Den udvikling, som i grundtræk er blevet dokumenteret for dansk, kan også konstateres i sprog, som er nært beslægtet hermed. Eksempelvis påviser Lagerholm (1999) en reduktion af periodens omfang i svensk sagprosa i tidsrummet 1800-1997, mens Admoni (1973) og andre demonstrerer, at periodens omfang i tysk mindskes fra det 17. til det 20. århundrede..$^{14} \mathrm{Om}$ end det er påfaldende, at moderne tysk opviser en kortere periodelængde end moderne dansk, må det fastholdes, at den gradvise reduktion af sætningskompleksitet ikke er et særligt dansk fænomen, men derimod en udviklingstendens af mere generel karakter. ${ }^{15}$

Ad B) Når den gradvise kompleksitetsreduktion skal forklares, er det oplagt at tage udgangspunkt $\mathrm{i}$ den relativt omfattende tysksprogede litteratur om emnet. Som udslagsgivende fremhæves her i reglen en række sprogeksterne forhold affødt af industrialiseringen:

Die gesellschaftlichen Umschichtungen, die Dominanz der Naturwissenschaften und der wirtschaftliche Aufschwung ließen einen einfacheren, sachlichen Sprachstil angemessener erscheinen als die stilistisch hohen sprachlichen Normen des Bildungsbürgertums. (Punkki-Roscher 1995: 15)

Selvom denne forklaring ikke kan afvises, er den ikke uproblematisk. Dels indfanger den ikke de omtalte forskelle mellem tysk på den ene side og dansk (og svensk) på den anden side - divergenser, som består, selvom disse sprogområder alle har gennemgået en industrialisering. Desuden tager reduktionen i sætningskompleksitet sin begyndelse, inden industrialiseringen sætter ind, hvilket må betyde, at også andre faktorer gør sig gældende. Fremtidig forskning bør undersøge disse forhold nærmere ud fra et kontrastivt-diakront perspektiv.

14 For yderligere litteratur om sætningskompleksitet i tysk henvises til det forskningshistoriske overblik i Christiansen (i trykken). En oversigt over litteratur om fænomenet i svensk findes hos Mertzlufft (2013).

15 Christiansen (i trykken) opgør den gennemsnitlige periodelængde i moderne tysk pressesprog til 15,5 ord pr. periode, i dansk til 20,5 ord pr. periode, jf. fodnote 13, og forklarer disse kontraster med udgangspunkt i syntakstypologiske forhold. 


\section{Konklusion}

Denne artikel giver en introduktion til den lingvistiske kompleksitetsforskning og præsenterer resultaterne af en diakront anlagt kompleksitetsanalyse af periodestrukturer i dansk. Med afsæt i en rekursionsbaseret tilgang til fænomenet operationaliseres syntaktisk kompleksitet som subordination på sætningsniveau. På denne baggrund analyseres et korpus bestående af uddrag af fire historiefaglige værker fordelt over det 18., 19., 20. og 21. århundrede. I løbet af dette tidsrum kan der konstateres en markant reduktion i sætningskompleksitet. Dette kommer bl.a. til udtryk ved, at antallet af delsætninger pr. periode, antallet af hypotaktiske storsætninger og antallet af bisætninger af højere grad mindskes. Da en lignende udvikling kan konstateres i svensk og tysk, synes der at være tale om en generel sproglig udviklingstendens, hvis årsager endnu ikke er udforsket til bunds.

\section{Litteratur}

\subsection{Korpus}

Allen, Carl Ferdinand: Haandbog i Fadrelandets Historie, 6. udgave. København 1863.

Arup, Erik: Danmarks Historie, 2. bog, bind A, uændret fotografisk optryk efter originaludgaven. København 1961.

Holberg, Ludvig: Dannemarks Riges Historie, bind 2, ny udgave. København 1856.

Ulsig, Erik: Konge og Råd 1440-1523, i: Steen Busck og Henning Poulsen (red.): Danmarks historie - i grundtrcek, 2. udgave. Aarhus 2002.

\subsection{Sekundærlitteratur}

Admoni, Wladimir: Die Entwicklungstendenzen des deutschen Satzbaus von heute. München 1973.

Baechler, Raffaela: Absolute Komplexität in der Nominalflexion. Althochdeutsch, Mittelhochdeutsch, Alemannisch und deutsche Standardsprache. Berlin 2017.

Blom, Jonas Nygaard: Syntactic Complexity in Danish Radio News, i: Nordicom Review 32, s. 93-109. Göteborg 2011.

Christiansen, Mads: Komplexität kontrastiv. Am Beispiel der Ganzsätze im Deutschen und Dänischen, i: Sprachwissenschaft. Heidelberg (i trykken).

- Subordinativ vs. koordinativ. Zur pränominalen Strapazierfähigkeit in deutschen und dänischen Pressetexten, i: Zeitschrift für germanistische Linguistik 46, s. 333-354. Berlin 2018. 
Culicover, Peter: Grammar and Complexity. Language at the Intersection of Competence and Performance. Oxford 2013.

Deutscher, Guy: »Overall complexity«: a wild goose chase?, i: Geoffrey Sampson, David Gil og Peter Trudgill (red.): Language Complexity as an Evolving Variable, s. 243-251. Oxford 2009.

Fischer, Klaus: Komplexität - dennoch ein nützlicher Begriff, i: Mathilde Hennig (red.): Linguistische Komplexität-ein Phantom?, s. 19-52. Tübingen 2017.

Hansen, Aage: Moderne Dansk, bind 1. København 1967.

Hennig, Mathilde (red.): Linguistische Komplexität - ein Phantom? Tübingen 2017a.

- Einleitung, i: Mathilde Hennig (red.): Linguistische Komplexität - ein Phantom?, s. 7-18. Tübingen 2017b.

- Strukturelle Komplexität attributiver Junktion, i: Mathilde Hennig og Robert Niemann (red.): Junktion in der Attribution. Ein Komplexitätsphänomen aus grammatischer, psycholinguistischer und praxistheoretischer Perspektive, s. 163-201. Berlin/Boston 2015.

Hennig, Mathilde, Volker Emmrich og Stephanie Lotzow: Komplexität und Koordination, i: Mathilde Hennig (red.): Linguistische Komplexität - ein Phantom?, s. 175-195. Tübingen 2017.

Hockett, Charles: A Course in Modern Linguistics. New York 1958.

Humboldt, Wilhelm von: Über die Verschiedenheit des menschlichen Sprachbaues und ihren Einfluss auf die geistige Entwickelung des Menschengeschlechts. Berlin 1836.

Karlsson, Fred: Origin and maintenance of clausal embedding complexity, i: Geoffrey Sampson (red.): Language Complexity as an Evolving Variable, s. 192-202. Oxford 2009.

Kortmann, Bernd og Benedikt Szmrecsanyi (red.): Linguistic Complexity. Second Language Acquisition, Indigenization, Contact. Berlin/Boston 2012a.

- Introduction: Linguistic complexity. Second Language Acquisition, indigenization, contact, i: Bernd Kortmann og Benedikt Szmrecsanyi (red.): Linguistic Complexity. Second Language Acquisition, Indigenization, Contact, s. 6-34. Berlin/Boston 2012b.

Kusters, Wouter: Complexity in linguistic theory, language learning and language change, i: Matti Miestamo, Kaius Sinnemäki og Fred Karlsson (red.): Language Complexity. Typology, contact, change, s. 3-22. Amsterdam 2008.

Lagerholm, Per: Talspråk i skrift. Om muntlighetens utveckling i svensk sakprosa 1800-1997. Lund 1999.

Mertzlufft, Christine: Nähe und Distanz im Kontrast. Deutsche und schwedische Behördentexte von 1950 bis heute. Hildesheim/Zürich/New York 2013.

Miestamo, Matti: Grammatical complexity in a cross-linguistic perspective, i: Matti Miestamo, Kaius Sinnemäki og Fred Karlsson (red.): Language Complexity: Typology, contact, change, s. 23-41. Amsterdam 2008.

Miestamo, Matti, Kaius Sinnemäki og Fred Karlsson (red.): Language Complexity: Typology, contact, change. Amsterdam 2008. 
Punkki-Roscher, Marja: Nominalstil in populärwissenschaftlichen Texten. Zur Syntax und Semantik der komplexen Nominalphrasen. Frankfurt am Main/ Berlin/Bern/New York/Paris/Wien 1995.

Sampson, Geoffrey: A linguistic axiom challenged, i: Geoffrey Sampson, David Gil og Peter Trudgill (red.): Language Complexity as an Evolving Variable, s. 1-18. Oxford 2009. 